\title{
Um provinciano que não o era
}

\author{
Daniel Maggetti
}

\section{Um escritor pouco conhecido}

Seja navegando na internet ou procurando em livros escolares franceses recentes ${ }^{1}$, o leitor que desconhece mas deseja descobrir Ramuz tem todas as chances de se ver confrontado com uma imagem estereotipada: um autor que une o talento de poeta rústico ao de escritor de montanha, um autor que permaneceu tão ligado à sua terra de origem que sua obra dela se tornou o reflexo fiel ${ }^{2}$. O rótulo de "regionalista", que a ele se colou já há muito tempo, mas que ele sempre recusou, parece ter se tornado a única forma de defini-lo. Desde então, o pouco espaço que lhe é geralmente dado na história literária francesa do século XX não surpreende mais, ficando evidente que o questionamento de Albert Béguin sobre tal assunto não teve qualquer efeito:

Não deveria ser permitido pronunciar sobre o assunto palavras como "romancista camponês" ou "escritor regionalista", que introduzem um falsa perspectiva".

Se possivelmente, no que diz respeito ao assunto, "a falsa perspectiva” se tornou norma no espaço literário francês desde os anos 1950, esta, à qual faz referência Béguin, tinha sido evitada pela elite de críticos e escritores enquanto Ramuz era vivo. Como lembra Jérôme Meizoz no prefácio de um número recente da revista Europe $e^{*}$, Spitzer, Giono, Claudel, Aragon e Céline, entre outros, entenderam perfeitamente a perspectiva estética ramuziana. Na Suíça romanda, por outro lado, mesmo se os leitores de referência tendem a situar

\footnotetext{
${ }^{1}$ Um estudo recente faz a esse propósito "um terrível balanço: os autores de manuais desconhecem Ramuz em 92\% dos casos, ou não julgam necessário citálo $[\ldots]$ e, quando a ele fazem referência, equivocam-se gravemente!" (Pierre, Jean-Louis. "Ramuz dans les manuels scolaires français", C. F. Ramuz 6: au carrefour des cultures et des esthétiques. Paris: Minard, 1998: 263).

${ }^{2} \mathrm{~A}$ única exceção sobre essa imagem caricatural se deve à evocação de sua colaboração com Igor Stravinsky para Histoire du soldat. Mas essa relação, circunscrita no tempo, em nada modifica a visão do conjunto.
}

"Béguin, Albert. Patience de Ramuz(1950). Neuchâtel: La Baconnière, 1978: 10.)

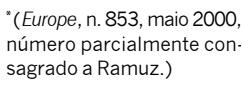


algumas vezes Ramuz na região do Valais, outras no Pays de Vaud, o valor e a condição especial de escritor nunca foram postos em dúvida: número de publicações, estudos e até mesmo marcas institucionais testemunham a convicção da qualidade desta obra. Um fato curioso é que Ramuz, que sempre foi reticente quanto à própria idéia de uma identidade suíça fora da estrita esfera política, foi há alguns anos "fetichizado" e sua figura se encontra desde então nas notas de duzentos francos, reconhecimento emblemático do lugar ocupado por ele no panteão literário confederativo, lugar este que evidentemente pertence a um clássico.

Essa diferença entre a consideração de que goza Ramuz na Suíça e o desconhecimento, ou até mesmo esquecimento, na França poderia ser vista como um efeito da lógica de pertencimento: sob o efeito da decantação do tempo, os provincianos continuam honrando o "grande homem", enquanto, no centro da arena, lá onde se toma a "verdadeira" medida das obras, o herói de outrora é percebido apenas como um coadjuvante. Mas essa visão simplista se esvai a partir do momento em que se toma em consideração a carreira do escritor e do grupo de artistas em que se inseria. A posição de Ramuz no campo literário de seu tempo, sua contribuição aos debates estéticos mais importantes, sua inscrição editorial, sua recepção, tudo isso converge para atestar que ele foi uma das figuras de proa da literatura do entreguerras, e com toda razão de tê-lo sido. Seu destino crítico, no entanto, é por ora claramente mais modesto do que o de seus "camaradas" (a comparação com Giono é particularmente reveladora), de onde se deduz que houve, no seu caso, fatores que o desfavoreceram.

A situação "periférica" de Ramuz foi, nesse sentido, um entrave à sua posteridade literária. Editado desde 1924 pela Grasset, ou pela Mermod em Lausanne, foi nesta editora que foram lançados, em 1940 e 1941, os vinte volumes de suas Cuvres complètes: desde então, muitos de seus romances circulam em duas versões, devido ao fato de a Grasset ter reimpresso uma versão do texto que não é a última, já que Ramuz revisou e corrigiu, algumas vezes de forma significativa, a totalidade de sua obra para a edição da Mermod, na qual se baseiam geralmente as reedições suíças. Impõese, antes de tudo, uma questão primeira não respondida 
sobre o texto de referência. Além disso, ainda não existe uma edição crítica da obra: sem anotações, raramente introduzidos e quase nunca comentados, romances, novelas e ensaios são propostos ao leitor de forma não contextualizada, o que encoraja a leitura "realista" das intrigas e não permite levar em conta, por exemplo, a audácia e a novidade das soluções narrativas e estilísticas experimentadas pelo autor. Tal situação tem impacto direto no contex to escolar, incluindo a universidade, e é nele que começa a espiral de não-conhecimento: pouco lido nos centros de ensino (na França, principalmente, onde a nacionalidade suíça pode ser considerada um inconveniente), Ramuz não encontra, conseqüentemente, críticos acadêmicos que se interessem por sua obra e que a valorizem simbolicamente, por meio de análises e aproximações que poderiam ser feitas. Ausente, ou quase isso, do circuito universitário francês, estudado sem continuidade, Ramuz não poderia obter um lugar de referência no âmbito da história literária: tendo se tornado restrito a um grupo de leitores pouco numeroso, composto de especialistas, sua posição é a de um autor confidencial. Na própria Suíça, a raridade, ou até mesmo a ausência explícita, de estruturas capazes de dar conta de maneira eficaz das obras de um escritor de sua dimensão certamente não favoreceu a difusão de sua obra. A organização do setor cultural suíço foi, durante muito tempo, responsabilidade de cada cantão separadamente: Ramuz foi, dessa forma, estudado e promovido sobretudo na região de Vaud, onde nasceu, e em cuja biblioteca, parceira essencial dos herdeiros do autor, ficou conservada a maior parte dos arquivos. Desde sua criação nos anos 1960, o Centro de Pesquisas em Letras Romandas da Universidade de Lausanne se empenhou na publicação de documentos destinados a delinear cuidadosamente o ambiente de trabalho do romancista $^{3}$. Apesar de constante, a pesquisa do centro foi sempre limitada pelo seu tamanho e pelos meios de que dispunha, não permitindo durante muito tempo, por exemplo, qual-

${ }^{3}$ Referimo-nos particularmente à publicação, feita por Gilbert Guisan, de um extensa coletânea de sua correspondência, acompanhada de documentos, nos seis volumes de C. F. Ramuz, ses amis et son temps (Lausanne-Paris: La Bibliothèque des Arts, 1967-1970). 
(Ramuz Charles-Ferdinand. Une province qui n'en est pas une [1938]. Lausanne: Ren contre, 1952: 17.)

"(: 17.) quer projeto de edição crítica. ${ }^{4}$ Como conseqüência, mesmo no seu país natal, Ramuz, por falta de acompanhamento adequado, acabou por ser considerado mais um autor de valor patrimonial e sentimental que um escritor cuja busca estética poderia ser ainda bem recebida.

Somam-se a esses elementos de geopolítica circunstâncias históricas particulares que explicam o esquecimento que recaiu sobre Ramuz. Tendo falecido logo depois da Segunda Guerra Mundial, o escritor não pôde atuar na reconstrução do campo literário de língua francesa que aconteceu durante os anos 1950 e 1960: o existencialismo e o Novo Romance orientaram a idéia que se faz de modernidade em uma direção particular, diferente da que ele havia explorado. O caráter aparentemente pouco atual da obra e o posicionamento de seu autor no território do "excêntrico" constituíram fatores desqualificantes diante da opinião pública.

\section{Uma forma de defesa: Une province qui n'en est pas une (1938)}

O estatuto de Ramuz na literatura de língua francesa deixa tanto a desejar que o escritor, ao longo de sua carreira, reflete sobre o problema de sua inserção no campo literário com base nas relações centro-periferia e tenta conciliar sua vontade de manter raízes com seu desejo de buscar a universalidade. Em um célebre texto de 1938, significativamente intitulado Une province qui n'en est pas une*, o escritor, no auge de sua carreira, retraça para o leitor o seu percurso, abordando simultaneamente a importância do elo identitário que o liga à região de Vaud, o aspecto para ele essencial do reconhecimento parisiense e sua própria concepção da língua. Ao criar um alter ego - o "jovem nascido em Vaud, ávido por se expressar", sentindo-se como alguém que "não encontra em lugar algum o modelo que lhe convém”* -, Ramuz explica por que esse jovem se volta obrigatoriamente em direção a Paris - onde ele próprio vivera mais da

\footnotetext{
${ }^{4}$ Não existe, nas estruturas universitárias e de pesquisa suíças, nenhuma instituição comparável ao CNRS francês, ao qual se deve um grande números de trabalhos de edição científica na França. Voltaremos a falar adiante dos trabalhos atuais, os quais estão em vias de superar tal impasse.
} 
metade de sua vida, entre o início do século XX e a Primeira Guerra Mundial:

Pois Paris, para nós suíços romandos, é antes de tudo a nossa capital. Deixo claro que não estou fazendo política; pretendo sublinhar apenas que Paris é a capital de uma língua, e que é portanto nossa capital porque essa língua é a nossa língua. [...] É que antes de tudo existe a língua. Ela é o signo por excelência da ligação entre os homens. [...] O uso comum do francês cria imediatamente um elo natural entre todos aqueles que falam francês. Ora, falamos francês por direito, isso quer dizer com os mesmos direitos dos que vivem em qualquer região da França.
Car Paris est quand même tout d'abord notre capitale, à nous autres Suisses romands. Il va bien sans dire que je ne fais pas ici de la politique; j’entends avancer seulement que Paris est la capitale d'une langue, et qu'il est notre capitale parce que cette langue est notre langue. [...] C'est qu'il y a d'abord la langue. Elle est le grand signe de ralliement des hommes. [...] l'usage commun du français crée aussitôt un lien naturel entre tous ceux qui parlent le français. Or nous parlons le français de plein droit, j'entends avec les droits égaux à ceux de toute autre province de France.*

Pondo-se na linha de frente, o romancista sublinha um elemento central, o fato de que essa língua, "como a de quase todas as regiões da França, não é absolutamente o francês escrito, o francês literário, o francês dos livros e dos jornais, mas um certo falar que se transmite de uma região a outra"*; daí a importância das especificidades expressivas dessa linguagem a partir de "uma certa inflexão"* que possui e de suas "nuanças infinitamente pequenas"* que, partindo do exemplo da liberdade expressiva que reina em Paris (a Paris do povo que fala, e não a Paris acadêmica, ou a Paris mundana), ele escolheu utilizar. Isso conduz a uma definição bastante aberta da língua literária:

Não acredito que a pureza de uma língua, qualquer que ela seja, resulte da destruição prévia dos germes nocivos que poderiam corrompê-la; não acredito que, enquanto um povo está vivo, a língua que ele fala possa ser conservada por vontade pró-
Je ne pense pas que la pureté d'une langue, quelle qu'elle soit, résulte de la destruction préalable des germes nocifs qui pourraient la corrompre; je ne pense pas que quand un peuple est vivant, la langue qu'il parle puisse être conservée à son intention 
pria numa geladeira. [...] A língua é a língua que se fala, não aquela que se encontra nas gramáticas; a língua que se fala vem primeiro, as gramáticas em seguida. Impregnada de gírias, de palavras estrangeiras, de toda a espécie de construções, que ela vai buscar nos dialetos do mundo inteiro, de todo tipo de elementos impuros, [...] nem por isso vive menos, vive até mais $[\cdots]$

Em contato com uma Paris com a qual nunca se fundiu, ouvindo as guinadas que os parisienses impõem à sua língua, Ramuz entendeu que a língua que ele procurava retranscrever, se estava em descompasso com as normas acadêmicas, não fugia aos "desvios" linguageiros urbanos. Daí ser possível falar de uma legitimação indireta do seu estilo, a qual acompanha uma espécie de "repatriamento" emblemático:

Foi desta forma que Paris não fez de mim um parisiense de segunda ordem, mas um verdadeiro Vaudois, alguém que se descobriu ainda mais Vaudois no momento da partida do que no momento da chegada. [...] Foi portanto Paris que me repatriou, que me devolveu a minha pátria, tal como ela era, com suas qualidades, se as tem, e seus defeitos; aceitando-os a priori, tanto aquelas quanto estes. dans une espèce de frigidaire. [...] La langue est la langue qu'on parle, non celle qu'on trouve dans les grammaires; la langue qu'on parle vient d'abord, les grammaires ne viennent qu'ensuite. Chargée de mots d'argot, de termes étrangers, de toute espèce de tournures qu'elle emprunte aujourd'hui aux dialectes du monde entier, de toute espèce d'éléments impurs, [ [...] elle n'en vit pas moins, sinon davantage $[\ldots]$.
C'est ainsi que Paris n'a pas fait de moi un Parisien de deuxième zone, mais bien un Vaudois renforcé, un Vaudois qui s'est trouvé bien plus Vaudois au moment de le quitter que quand il y était venu. [...] C'est donc Paris qui m’a rapatrié, lui qui m’a rendu à ma terre, telle qu'elle était, avec ses qualités, si elle en a, mais ses défauts; et, de plus, en les acceptant d'avance, celles-là comme ceux-ci. ${ }^{*}$

É, pois, de forma dupla que Ramuz explica a escolha de explorar, em sua obra, a realidade que lhe é familiar, seja ela alpestre, lacustre ou vinícola. Por um lado, deixa entender que, para ele, é somente ao se interessar pelo que lhe é intimamente próximo que o escritor pode chegar a uma criação autêntica: essa representação orgânica da ligação entre o artista e o universo no qual ele se aprofunda é capital em Ramuz. 
Por outro, essa tomada de consciência implica logicamente a utilização de um estilo específico, que se adapta também à realidade expressa - um estilo que, como vimos, Ramuz legitima não necessariamente no plano interno, mas visando às instâncias de julgamento e consagração parisienses. ${ }^{5}$

\section{O particular e o universal, um desafio impossível?}

Não teríamos nós acabado de demonstrar que Ramuz, conduzido por um desejo de proximidade que o leva a se inserir no lugar de que fala, faz-se porta-voz de uma forma de determinismo do qual seus textos são uma espécie de manifesto? Não ficamos imersos a partir de então num particularismo que se aproxima do regionalismo tão execrado? Sua obra não seria quase um desvio de um certo modo de glorificar sua terra de origem? Chegar a essa conclusão, como alguns o fizeram, significaria trair o projeto e a visão do escritor. Ao discutir, como vimos, os mecanismos de dominação simbólica, o escritor sempre tentou ultrapassar a oposição entre o particular e o universal, para estender seus esforços a outro terreno. $\mathrm{O}$ que interessa prioritariamente a Ramuz, e orienta sua busca, é ao mesmo tempo a vontade de trabalhar a lín-

\footnotetext{
${ }^{5}$ A consciência que Ramuz possui dos mecanismos de consagração e de sua importância no plano do mercado dos bens simbólicos é particularmente visível no fim de seu texto: "Nem por isso Paris deixa de ser quem consagra. Nem por isso Paris deixa de ser quem permite às províncias desabrocharem e serem representadas por ela; nem por isso deixa de ser a civilização francesa devedora de Paris por seu desenvolvimento tão amplo". ["Mais ce n'en est pas moins Paris qui consacre. Ce n'en est pas moins Paris qui a permis aux provinces d'éclore et comme de se résumer en lui; ce n'en est pas moins à Paris que la civilisation française est redevable de son développement si complet".] (: 34); "Paris não deve ser a capital de uma parte da nação, mas da nação inteira: seu papel é de recolher e de consagrar. Paris é a soma das diferentes províncias e uma espécie de concerto composto por todas essas vozes associadas; eu teria desejado que meu pequeno país e a minha província (apesar de ela não ser uma, já que se encontra para além de uma fronteira) legassem sua parte a este concerto, uma pequena parte, mas a sua própria parte, mesmo que sua voz fosse rouca e desafinada, porque Paris é definitivamente o ponto de chegada (em todos os sentidos da palavra) do campesinato francês ou de língua francesa". ["Paris ne doit pas être la capitale d'une partie de la nation, mais de la nation toute entière: son rôle est de recueillir et de consacrer. Il est la somme des différentes provinces et une espèce de concert fait de toutes ces voix associées; j'aurais voulu que mon petit pays à moi et ma province (bien qu'elle n'en soit pas une, puisqu'elle est située au-delà d'une frontière) apportât sa partie à ce concert, une petite partie, mais sa propre partie, même si sa voix était rauque et mal accordée, car Paris n'en reste pas moins le point d'aboutissement (à tous les sens du mot) de la paysannerie française et de celle qui parle le français".] (: 35).
} 
"(Béguin, Albert. Patience de Ramuz. Ob. cit.: 11.) gua e o desejo de iluminar, desse modo, sentimentos e funcionamentos tanto individuais quanto coletivos, que são - e disso estava persuadido - próprios à condição humana; todos os homens os recebem como herança, sejam quais forem suas origens, sua situação social, ou a época em que vivem. Essa proposta, assinalada por uma concepção clássica do mundo, explica por que Ramuz tem como referência tanto autores da Antigüidade quanto os livros da Bíblia, que constituem de certo modo a estrutura com base na qual ele reescreve a aventura do homem, sua experiência da solidão, sua relação com o outro, com o amor, com a metafísica. Entende-se desse modo seu gosto pelos universos arcaicos e primitivos. Contrariamente ao que acontece nas sociedades "modernas", essa "natureza humana" na qual ele acredita manifesta-se na sua obra com poucos artifícios e, por isso mesmo, de forma mais intensa. Essa orientação fundamental, em que o pertencimento singular é imediatamente posto em relação com o sentido do conjunto que o transcende, foi resumida por Albert Béguin da seguinte forma:

[...] Ramuz, ao buscar "reunir" os homens no que eles têm de mais universal, compreendeu logo que não seria capaz de encontrar nem de exprimir o fundamento humano se não fosse escolhendo para seus heróis seres com os quais estava ligado por marcas nativas*.

Essa leitura é possivelmente a única capaz de fazer justiça à tentativa estética de Ramuz. Mas retomar o que disse Béguin, repeti-lo e comprová-lo com citações e provas pessoais não basta para legitimá-la. Isso porque a circulação das produções artísticas se inscreve em um campo de tensão, caracterizado pelas relações de força e pelas diferenças de legitimação simbólica. O "particular" a que Ramuz se refere, que é a soma do periférico e do rústico, torna-se assim simbolicamente mais deficitário que outras realidades, tão particulares quanto ao que diz respeito aos fatos, mas cuja "universabilidade" levanta menos problemas para as instâncias detentoras do poder de consagração, instâncias que, no domínio literário francófono, são marcadas por uma inegável tendência ao franco-, quiçá ao luteciocentrismo. Daí a condescendência ou o desdém com que Ramuz pode ser tratado, ele que não é nem parisiense, nem urbano, nem mesmo francês, e em vários níveis desconectado daquilo que se convencionou chamar "contempo- 
râneo". A mudança que se anuncia no momento atual e que provavelmente levará a uma reconsideração do estatuto do nosso autor se apóia em elementos que são "universalizáveis", tais como o interesse estilístico dos textos de Ramuz, o olhar que ele lança sobre a língua francesa e a utilização que faz dela. Privilegiando essa chave de análise, é possível pôr entre parênteses, como acessórios, os aspectos que, de um ponto de vista referencial, parecem excessivamente marcados para um leitor parisiense. É, aliás, essa chave, acrescida de um balanço histórico objetivo, que abriu a Ramuz as portas da "Bibliotheque de la Pléiade" nas edições Gallimard. Pode ser que o lançamento do conjunto da obra romanesca nessa coleção de prestígio, prevista para 2006 e atualmente em preparação, leve a uma "reclassificação" de Ramuz, que ficará, a partir de então, em termos de hierarquia editorial, no mesmo nível dos colegas que eram seus interlocutores. Essa publicação deveria, portanto, desempenhar o papel de instrumento de equilíbrio, conferindo a Ramuz aquela porção de valor simbólico que ele ainda não recebeu. Deveria também servir para estabelecer uma versão confiável e devidamente anotada e comentada dos textos do escritor, dando, ao menos em parte, acesso ao seu laboratório de trabalho e à complexa gênese de suas obras, acesso que ficará ainda mais aberto ao longo do próximo decênio, com a publicação de uma edição comentada das Euvres complètes. O primeiro volume - o Journal, em versão integral - será lançado em Genebra, pela editora Slatkine, em 2006, inaugurando um projeto que dará conta do romancista, do ensaísta, do poeta. Ninguém duvida que, juntos, esses volumes permitirão estudar e conhecer melhor Ramuz na França e fora dela, contribuindo para resgatá-lo de meio século de purgatório e reintegrá-lo, enfim, ao circuito dos escritores que marcaram o século XX.

Tradução: Daniela Cerdeira da Silva 
Daniel Maggetti

É professor da Universidade de Lausanne e diretor do Centro de Pesquisa em Letras Romandas. É autor de numerosos estudos - históricos, sociológicos e monográficos -, primordialmente sobre a literatura suíça romanda, e co-dirige, com Roger Francillon, a edição das Obras completas de Ramuz, a ser publicada em Genebra pelas Edições Slatkine.

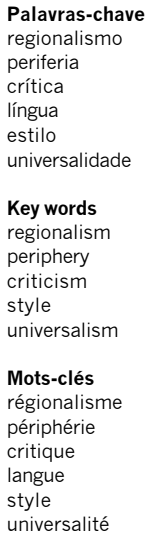

Recebido em 31/10/2003

Aprovado em 15/03/2004

\section{Resumo}

Se Ramuz não é hoje muito conhecido, tal não era o caso quando vivo. A condição periférica do escritor, a história da edição de suas obras, as orientações (mal compreendidas) de sua estética explicam essa situação. A edição de seus romances na Bibliothèque de la Pléiade, da editora Gallimard, deve levar a uma "reclassificação" de Ramuz, que assim reencontraria seu lugar ao lado dos escritores que marcaram o século XX.

\begin{abstract}
If Ramuz is not well known today, such was not the case during his lifetime. His peripheral condition as writer, the history surrounding the publication of his works, the (misunderstood) orientations of his aesthetics account for this situation. The publication of his novels at the "Bibliothèque de la Pléiade" should bring about a "reclassification" of Ramuz, who would then find anew his proper place at the side of the writers who left their mark in the XX century.
\end{abstract}

\section{Résumé}

Si Ramuz est aujourd'hui mal connu, tel ne fut pas le cas de son vivant. La situation périphérique de l'écrivain, l'histoire de l'édition de ses œuvres, les orientations (mal comprises) de son esthétique expliquent cette situation. L'édition de ses romans dans la "Bibliothèque de la Pléiade" des Editions Gallimard devrait avoir comme conséquence un "reclassement" de Ramuz, qui retrouverait par là sa place au côté des écrivains qui ont marqué le $\mathrm{XX}^{\mathrm{e}}$ siècle. 